\title{
Andrographolide Inhibits Inflammatory Cytokines Secretion in LPS-Stimulated RAW264.7 Cells through Suppression of NF- $\kappa$ B/MAPK Signaling Pathway
}

\author{
Yu Li, ${ }^{1}$ Shengnan He, ${ }^{1}$ Jishun Tang, ${ }^{2}$ Nana Ding, ${ }^{1}$ Xiaoyan Chu, \\ Lianping Cheng, ${ }^{1}$ Xuedong Ding, ${ }^{1}$ Ting Liang, ${ }^{1}$ Shibin Feng, ${ }^{1}$ Sajid Ur Rahman, \\ Xichun Wang, ${ }^{1}$ and Jinjie $\mathrm{Wu}^{1}$ \\ ${ }^{1}$ College of Animal Science and Technology, Anhui Agricultural University, 130 West Changjiang Road, Hefei 230036, China \\ ${ }^{2}$ Institute of Animal Husbandry and Veterinary Medicine, Anhui Academy of Agriculture Sciences, Nongkenan Road, \\ Hefei 230031, China \\ Correspondence should be addressed to Jinjie Wu; wjj@ahau.edu.cn
}

Received 24 January 2017; Revised 16 March 2017; Accepted 11 April 2017; Published 7 June 2017

Academic Editor: Emilio Lizarraga

Copyright (c) $2017 \mathrm{Yu} \mathrm{Li} \mathrm{et} \mathrm{al.} \mathrm{This} \mathrm{is} \mathrm{an} \mathrm{open} \mathrm{access} \mathrm{article} \mathrm{distributed} \mathrm{under} \mathrm{the} \mathrm{Creative} \mathrm{Commons} \mathrm{Attribution} \mathrm{License,} \mathrm{which}$ permits unrestricted use, distribution, and reproduction in any medium, provided the original work is properly cited.

\begin{abstract}
Andrographolide, the main active component extracted from Andrographis paniculata (Burm.f.) Wall. ex Nees, exerts antiinflammatory effects; however, the principal molecular mechanisms remain unclear. The objective of this study was to investigate the molecular mechanisms of Andrographolide in modifying lipopolysaccharide- (LPS-) induced signaling pathway in RAW264.7 cells. An in vitro model of inflammation was induced by LPS in mouse RAW264.7 cells in the presence of Andrographolide. The concentration and expression levels of proinflammatory cytokines were determined by an enzyme-linked immunosorbent assay (ELISA) and quantitative real-time polymerase chain reaction (qRT-PCR), respectively. The nuclear level of NF- $\kappa$ B was measured by an electrophoretic mobility shift assay (EMSA). The expression levels of NF- $\kappa$ B, p38, ERK, and JNK were determined by western blot. Andrographolide dose-dependently inhibited the release and mRNA expression of TNF- $\alpha$, IL- 6 , and IL- $1 \beta$ in LPS-stimulated RAW264.7 cells. The nuclear level of p65 protein was decreased in Andrographolide treatment group. Western blot analysis showed that Andrographolide suppressed LPS-induced NF- $\kappa$ B activation and the phosphorylation of IkBa, ERK1/2, JNK, and p38. These results suggest that Andrographolide exerts an anti-inflammatory effect by inhibiting the activation of NF- $\kappa \mathrm{B} / \mathrm{MAPK}$ signaling pathway and the induction of proinflammatory cytokines.
\end{abstract}

\section{Introduction}

Inflammation is a complex reaction that occurs within local or systemic animal organs in response to multiple endogenous or exogenous injuries, which mainly result in redness, swelling, fever, pain of organs, and tissue damage [1]. The Andrographis paniculata plant has been widely used for long periods in Asian traditional medicinal [2]. Common Andrographis herb is derived from Andrographis paniculata (Burm.f.) Wall. ex Nees. The whole plant or aerial parts of plant are employed for the purposes like cooling properties and a bitter taste that can reduce heat, detoxify, cool the blood, and reduce swellings [3]. Andrographolide $\left(\mathrm{C}_{20} \mathrm{H}_{30} \mathrm{O}_{5}\right.$, Figure 1), a labdane diterpenoid that is produced by Andrographis paniculata plant, has been reported to have several pharmacological properties, including antibacterial, antiviral, and antiplatelet properties, stimulation of cell differentiation, protection of the liver, being a cholagogue, antitumor properties, and immunoregulation [4]. Previous studies reported that Andrographolide can inhibit the increase in capillary permeability caused by xylene and acetic acid in mice. Moreover, Andrographolide has exhibited obvious antiinflammatory properties in response to the rat model of hind paw edema induced by egg white protein and carrageenan [5]. Andrographolide can inhibit the expression of inducible nitric oxide synthase (iNOS) by LPS-activated macrophages and the production of prostaglandin E2 [6]. However, the potential pharmacodynamic function and mechanisms by 


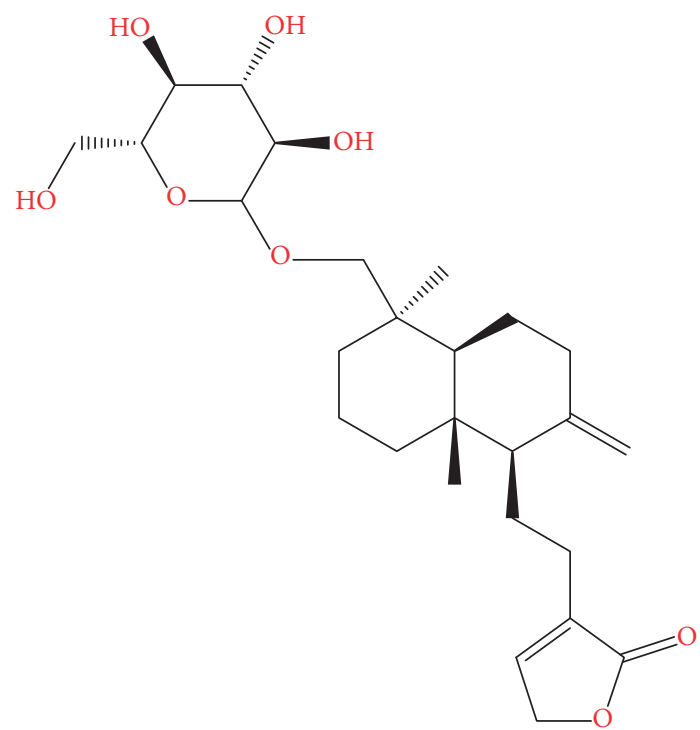

FIgURE 1: The chemical structure of Andrographolide.

which Andrographolide exerts such anti-inflammatory properties remains unclear [7].

LPS is considered as one of the most potent inducers of proinflammatory factors [8], and bacterial infections often cause a strong inflammatory reaction. Macrophages are important immune activating cells and play a critical role in the induction of the inflammatory response in response to pathogen invasion [9]. Mouse macrophage RAW264.7 cells stimulated by LPS can produce inflammatory mediators and inflammatory factor, such as TNF- $\alpha$, IL-1 $\beta$, and IL-6 [10, 11]. Therefore, an excessive production of these proinflammatory cytokines can cause severe damage to surrounding tissues.

Studies have confirmed that LPS induces inflammation primarily by stimulating NF- $\kappa$ B and the MAPK signaling pathway [12]. Therefore, inhibition of the inflammatory response by targeting signal transduction pathways has become a novel avenue for the treatment of inflammation.

In the present study, LPS was used to activate the NF- $\kappa \mathrm{B}$ and MAPK signaling pathways as the theoretical basis to investigate mechanisms of the anti-inflammatory effects of Andrographolide in LPS-induced inflammation of RAW264.7 cells. The aim of current investigation was to provide a theoretical basis for the further development of anti-inflammatory drugs.

\section{Materials and Methods}

2.1. Reagents. Andrographolide (Control of Pharmaceutical and Biological Product, Beijing, China), dimethyl sulfoxide (DMSO), fetal bovine serum, and $0.25 \%$ trypsin were purchased from HyClone (Logan, UT, USA); LPS (Escherichia coli 055:B5) was purchased from Sigma Chemical CO. (St. Louis, MO, USA); Mouse TNF- $\alpha$, IL-1 $\beta$, and IL-6 ELISA kits were purchased from Sbjbio company (Nanjing, China); primary antibodies of rabbit $\mathrm{mAb}$ p65, rabbit $\mathrm{mAb}$ ERK, and rabbit $\mathrm{mAb} J N K$; secondary antibodies of goat anti-rabbit IgG antibody; and goat anti-mouse IgG antibody were purchased from Wuhan Boster Biological Engineering Co. (Wuhan, China); primary antibodies of rabbit $\mathrm{mAb} \mathrm{I} \kappa \mathrm{B} \alpha$, mouse $\mathrm{mAb}$ phospho-I $\kappa \mathrm{B} \alpha$, mouse $\mathrm{mAb}$ phospho-p65, mouse $\mathrm{mAb}$ phospho-p38, mouse mAb phospho-specific p42-p44 ERK, and mouse $\mathrm{mAb}$ phospho-specific p46-p54 JNK were purchased from Beyotime Biotechnology Co. (Nanjing, China).

2.2. Culture of RAW264.7 Cells. RAW264.7 mouse monocyte-macrophage cells were received as a gift from Jilin University (Changchun, China). RAW264.7 cells were inoculated in cell culture bottles, and then the cells were placed in an incubator at $37^{\circ} \mathrm{C}$ and $5 \% \mathrm{CO}_{2}$. The culture medium (DMEM medium with $10 \%$ fetal bovine serum, $1 \% \mathrm{Gln}$, and $100 \mathrm{U} / \mathrm{ml}$ penicillin-streptomycin) were changed according to the cell growth conditions and color of the media, respectively. When the cells reached $80 \%$ confluence, the cells were subcultured by replacing the culture medium and the adherent cells were aspirated with a pipette, washed, and then seeded into new cell culture bottles to be incubated.

2.3. Microscopic Observation and Cell Counting Kit-8 (CCK8) Assay for Cell Viability. Briefly, RAW264.7 cells in the logarithmic phase were plated at a density of $1 \times 10^{5}$ cells $/ \mathrm{ml}$ into 96-well plates in a $37^{\circ} \mathrm{C}, 5 \% \mathrm{CO}_{2}$ incubator for $24 \mathrm{~h}$. Subsequently, $100 \mu \mathrm{L}$ cells were added to each well, and the cells were treated with indicated concentrations of Andrographolide for $1 \mathrm{~h}$ in the incubator. When the cell morphology observed by microscope was adequate, the same concentration was being performed in triplicate, followed by stimulating with $1 \mu \mathrm{g} / \mathrm{ml}$ LPS in a $37^{\circ} \mathrm{C}, 5 \% \mathrm{CO}_{2}$ incubator for $18 \mathrm{~h}$. A volume of $10 \mu \mathrm{L}$ CCK-8 (Dojindo, Kumamoto, Japan) was added to each well, and the cells were further incubated for additional 1-4h. The optical density (OD) was measured at $450 \mathrm{~nm}$ using a Bio-Rad Model 550 Microplate Reader (Bio-Rad, Hercules, CA, USA), and the cell viability was calculated.

2.4. ELISA Assay for the Contents of Proinflammatory Cytokines. The RAW264.7 cells $\left(2 \times 10^{6}\right.$ cells $/ \mathrm{ml}$, with $2 \mathrm{ml}$ in each well) were seeded into six-well plates and incubated in the presence of different concentrations $(6.25,12.5$, and $25 \mu \mathrm{g} / \mathrm{ml}$ ) of Andrographolide for $1 \mathrm{~h}$, followed by stimulating with LPS $(1 \mu \mathrm{g} / \mathrm{ml})$ for $18 \mathrm{~h}$ [13]. The cell-free supernatants were subsequently employed to quantify the contents of proinflammatory cytokines (TNF- $\alpha$, IL-1 $\beta$, and IL-6) using a mouse ELISA kit, according to the manufacturer's instructions (Sbjbio company, Nanjing, China).

2.5. Total RNA Isolation and $q R T-P C R$. The RAW 264.7 cells $\left(2 \times 10^{6} \mathrm{cells} / \mathrm{ml}\right.$, with $2 \mathrm{ml}$ in each well $)$ were seeded into sixwell plates and incubated in the presence of different concentrations $(6.25,12.5$, and $25 \mu \mathrm{g} / \mathrm{ml})$ of Andrographolide for $1 \mathrm{~h}$, followed by stimulation with LPS $(1 \mu \mathrm{g} / \mathrm{ml})$ for $18 \mathrm{~h}$. The supernatant was removed, and the sediments were washed with PBS twice. The total RNA was extracted using Trizol reagent following the manufacturer's instructions (TaKaRa, Dalian, China), and the RNA was reverse-transcribed into cDNA according to the Reverse Transcription System's 
TABLE 1: The TNF- $\alpha$, IL-1 $\beta$, and IL- 6 primers.

\begin{tabular}{lccc}
\hline Genes & Primer & Sequence $5^{\prime} \rightarrow 3^{\prime}$ & Product size $(\mathrm{bp})$ \\
\hline \multirow{2}{*}{$T N F-\alpha$} & Sense & GTCTCAGCCTCTTCTCATTC & 128 \\
& Antisense & CATAGAACTGATGAGAGGGA & 101 \\
$I L-1 \beta$ & Sense & AAATACCTGTGGCCTTGGGC & 125 \\
& Antisense & CTTGGGATCCACACTCTCCAG & \\
& Sense & GAGTCCTTCAGAGAGATACAG & 134 \\
& Antisense & CTGTGACTCCAGCTTATCTG & \\
& Sense & CTTCATTGACCTCAACTACATGG & \\
\hline
\end{tabular}

instructions (TaKaRa, Dalian, China). According to the GenBank sequence, the primer sequence of the target genes (i.e., TNF- $\alpha$, IL- $1 \beta$, and IL-6) and the $\beta$-actin gene were designed using the software Primer Premier 5.0 (Table 1). The amplification products were analyzed by $1.5 \%$ agarose gel electrophoresis and a gel imaging and analysis system (UVItec, Cambridge, UK).

2.6. EMSA Assay for Protein Transportation to the Nucleus. RAW264.7 cells $\left(2 \times 10^{6}\right.$ cells $/ \mathrm{ml}$, with $1 \mathrm{ml}$ in each well) were seeded into six-well plates; $2 \mathrm{ml}$ was added to each plate and incubated in the presence of different concentrations (6.25, 12.5 , and $25 \mu \mathrm{g} / \mathrm{ml}$ ) of Andrographolide for $1 \mathrm{~h}$ when the cells reached $5 \times 10^{6} \sim 1 \times 10^{7}$ cells $/ \mathrm{ml}$. Following this incubation, the cells were stimulated with LPS $(1 \mu \mathrm{g} / \mathrm{ml})$ for $18 \mathrm{~h}$; after that cells were collected and washed twice with ice-cold PBS, centrifuged at $500 \mathrm{~g}$ and $4^{\circ} \mathrm{C}$ for $3 \mathrm{~min}$, the supernatant was removed, and packed cell volume was estimated. The nucleoprotein was extracted with nuclear protein extraction reagent (Sagon, Shanghai, China) and the total protein was determined using the Bradford method (Biosharp, China). A $6.5 \%$ polyacrylamide gel was produced and made into a gel slab, an EMSA binding reaction was performed, and the samples were produced and dispensed.

Electrophoresis was initiated with a $0.5 \mathrm{x}$ TBE as the running buffer at $10 \mathrm{~V} / \mathrm{cm}$. When the bromophenol blue in the EMSA/Gel-Shift loading buffer ran to the lower edge of the gel, the electrophoresis was stopped. The required gel was cut, and the protein and probe $\left(5^{\prime}\right.$-AGTTGAGGGGACTTTCCCAGGC- $3^{\prime}$ ) complexes were transferred into a nylon membrane (GE Healthcare, USA) with a transfer buffer at $254 \mathrm{~nm}, 120 \mathrm{~mJ} / \mathrm{cm}^{2}$ in the cross-linking machine. After 45-60 s, cross-linking was completed, the sealing and washing liquid was dissolved at $37-50^{\circ} \mathrm{C}$ in a water bath, the nylon membrane was blocked with $15 \mathrm{ml}$ sealing liquid for $15 \mathrm{~min}$ on a horizontal rotator, and the sealing liquid was removed. The new sealing liquid containing streptavidinHRP conjugate (1:2000 dilution) was introduced; the membrane was shaken for 15 minutes on the horizontal rotator, followed by washing $(4 \times 5 \mathrm{~min})$ with the washing liquid. The nylon membrane was then placed in a container with 20-25 $\mathrm{ml}$ of a determined equilibrium liquid and shook for $5 \mathrm{~min}$. Then the nylon membrane was removed and the extra liquid was absorbed with absorbent paper. The chemiluminescent nucleic acid detection module working solution was added until the membrane was covered completely and then left at room temperature for 2-3 min. The nylon membrane was removed and the extra liquid was placed into the middle of two pieces of plastic wrap and tested using the G:BOX chemiXR5 Gel Imaging System. The results were analyzed using the Gel-Pro32 software (Syngene, Cambridge, $\mathrm{UK})$.

2.7. Western Blot Analysis. RAW 264.7 cells at $4 \times 10^{5}$ cells $/ \mathrm{ml}$ were seeded into six-well plates ( $2 \mathrm{ml}$ per plate) and incubated for $24 \mathrm{~h}$ and then pretreated with different concentrations $(6.25,12.5$, and $25 \mu \mathrm{g} / \mathrm{ml})$ of Andrographolide for $1 \mathrm{~h}$. The cells were stimulated with LPS $(1 \mu \mathrm{g} / \mathrm{ml})$ for $18 \mathrm{~h}$ and then collected and washed twice with ice-cold PBS. The total protein from the cells was extracted using a RIPA lysis buffer solution (Wuhan Boster Biological Engineering Co., Wuhan, China), and the total protein concentration was determined using a BCA Protein Assay Kit (Beyotime Inst. Biotech, Peking, China). The protein was split and the SDS-PAGE loading buffer (Beyotime Biotechnology Co., Shanghai, China) was added and placed into a $100^{\circ} \mathrm{C}$ water bath for $10 \mathrm{~min}$ and preserved at $4^{\circ} \mathrm{C}$ for later use.

The gel board was installed; a $12 \%$ separating gel and $15 \%$ stacking gel were produced; then five samples of proteins were added. Electrophoresis was initiated at $80 \mathrm{~V}$ and changed to $120 \mathrm{~V}$ after $25 \mathrm{~min}$ and continued until the samples run to the bottom of the gel. The required gel was cut and transferred into a PVDF membrane (Shanghai Jinsheng Biological Engineering Co) with electrophoresis buffer. The resulting membrane was blocked with $5 \%$ BSA for $4 \mathrm{~h}$ on a horizontal rotator at room temperature and then incubated with the primary antibodies at $4^{\circ} \mathrm{C}$ overnight. Subsequently, the membrane was washed with TBST three times followed by an incubation on the horizontal rotator for $5 \mathrm{~min}$ and incubated with the secondary antibody at room temperature for $45 \mathrm{~min}$ on the horizontal rotator. The blots were washed again with TBST three times for $5 \mathrm{~min}$ and then tested by the Gel Imaging System (Bio-Rad, Hercules, CA, USA). The results were analyzed using quantity one software (Bio-Rad, Hercules, CA, USA).

2.8. Statistical Analysis. Date were presented as mean \pm SEM. Differences between the mean values of the normally distributed data were analyzed using one-way ANOVA (Dunnett's $t$-test) and a two-tailed Student's $t$-test. The criterion for the differences was considered significant at $P<0.05$ or $P<0.01$ in all studies. 

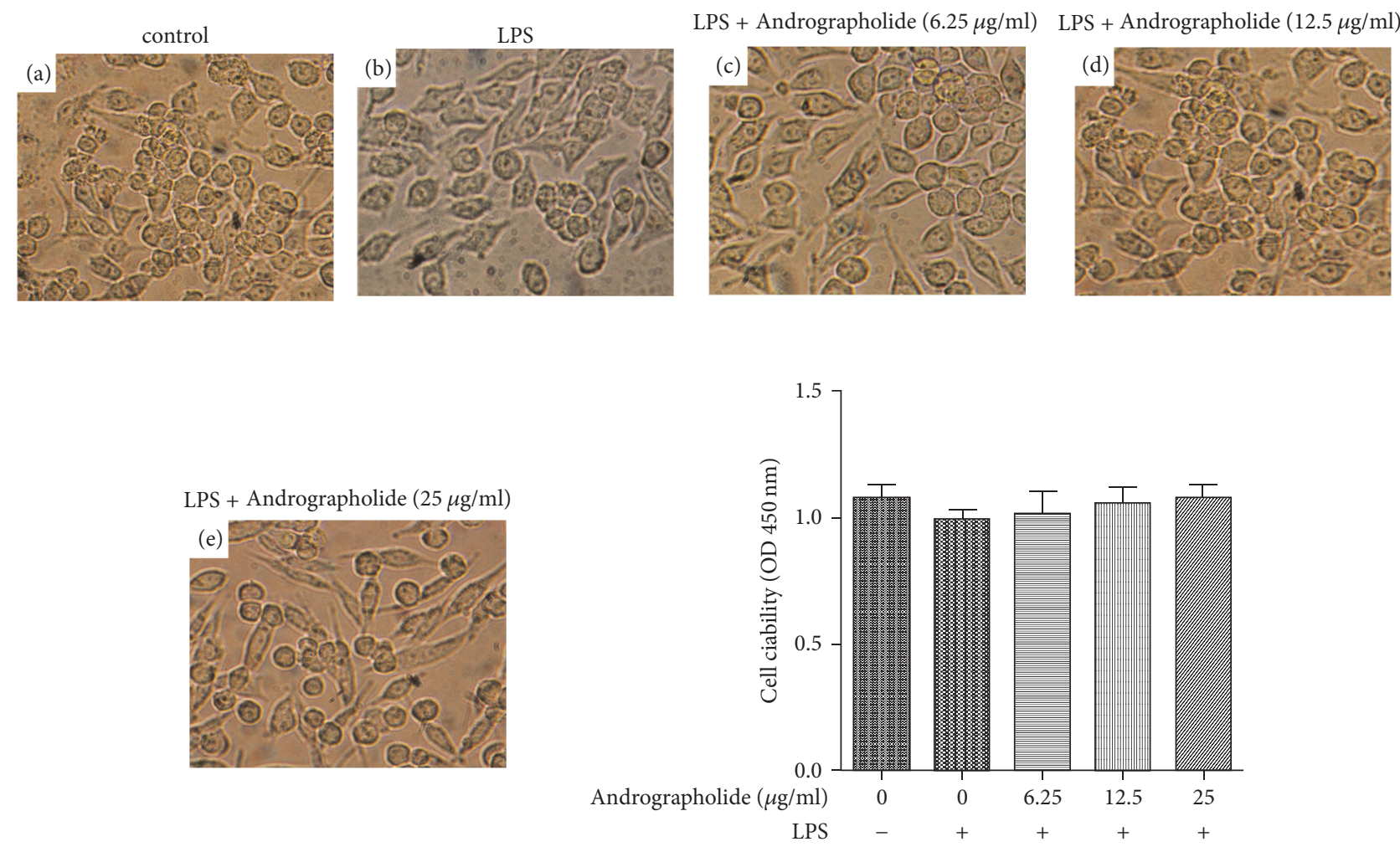

(f)

FIGURE 2: Effect of Andrographolide on morphologic changes and viability of RAW264.7 cells. (a) represents cells in control group; (b) represents cells treated by LPS; (c)-(e) represent cells treated with different concentration Andrographolide (6.25, 12.5, and 25 $\mu \mathrm{g} / \mathrm{ml})$ for $1 \mathrm{~h}$ and LPS for another $18 \mathrm{~h}$, respectively; (f) represents the effect of Andrographolide on the cell viability of RAW264.7 cells in control, LPS, and Andrographolide treated groups. Results are representative of three (f) independent experiments.

\section{Results}

3.1. Effect of Andrographolide on Cell Viability. To evaluate the effects of Andrographolide $(6.25,12.5$, and $25 \mathrm{~g} / \mathrm{ml}$ ) on RAW264.7 cells morphologic changes and viability, we performed inverted light microscopy (Nikon, Tokyo, Japan) and CCK-8 assay. As shown in Figures 2(a)-2(f), the cell morphology and viability of RAW264.7 cells have no recognizable changes with the increasing of Andrographolide concentrations. Cell viability in experimental groups with different doses of Andrographolide did not show any significant difference compared with the control group. These results indicated that the Andrographolide used in this study has no toxic effect.

3.2. Effect of Andrographolide on the Secretion of Proinflammatory Cytokines in LPS-Stimulated RAW264.7 Cells. To evaluate the effects of Andrographolide on the secretion of the proinflammatory cytokines in LPS-stimulated RAW264.7 cells, we measured the level of each cytokine using an ELISA. As presented in Figures 3(a)-3(c), the levels of proinflammatory cytokine in the LPS group were significantly higher than that in the control group $(P<0.05)$. Moreover, the proinflammatory cytokine levels of the Andrographolide groups (doses of $6.25,12.5$, and $25 \mathrm{~g} / \mathrm{ml}$ ) were significantly lower than that in the LPS group $(P<0.05$ or $P<$
0.01 ) and gradually decreased with the increasing doses of Andrographolide.

3.3. Effect of Andrographolide on the Expression Level of the Proinflammatory Cytokines in LPS-Stimulated RAW264.7 Cells. Next, we sought to evaluate the effects of Andrographolide on the expression level of the proinflammatory cytokines in LPS-stimulated RAW264.7 cells by qRT-PCR. As shown in Figures 4(a)-4(c), the mRNA expression levels of the proinflammatory cytokines in the LPS group were significantly higher than that in the control group $(P<0.05)$. Moreover, the mRNA expression levels of the proinflammatory cytokines in the Andrographolide groups (doses of 6.25, 12.5 , and $25 \mathrm{~g} / \mathrm{ml}$ ) were significantly lower than that in the LPS group $(P<0.01)$ and decreased in a dose-dependent manner.

3.4. Effect of Andrographolide on the Nuclear Level of NF- $k B$ Probe Binding Activity. We evaluated the effect of Andrographolide on the NF- $\kappa \mathrm{B}$ probe binding activity in NF$\kappa \mathrm{B}$ pathway. Figure 5 showed that the nuclear level of NF$\mathrm{kB}$ probe binding activity in LPS group was significantly higher than that in the control group $(P<0.01)$. However, the nuclear level of NF-kB probe binding activity is significantly decreased in the nuclear extract obtained from 


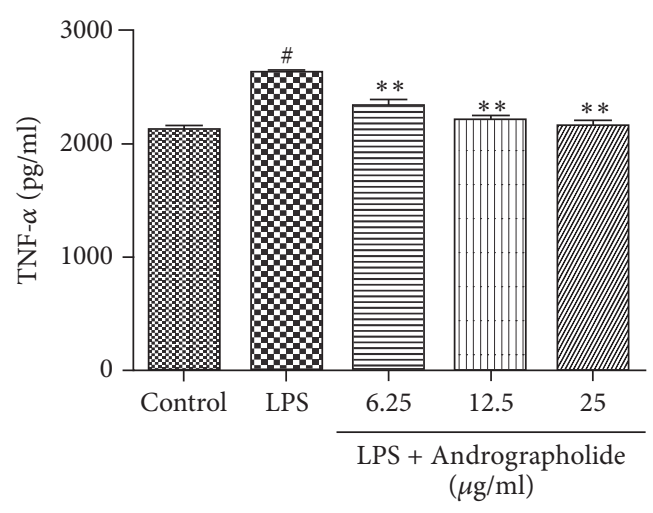

(a)

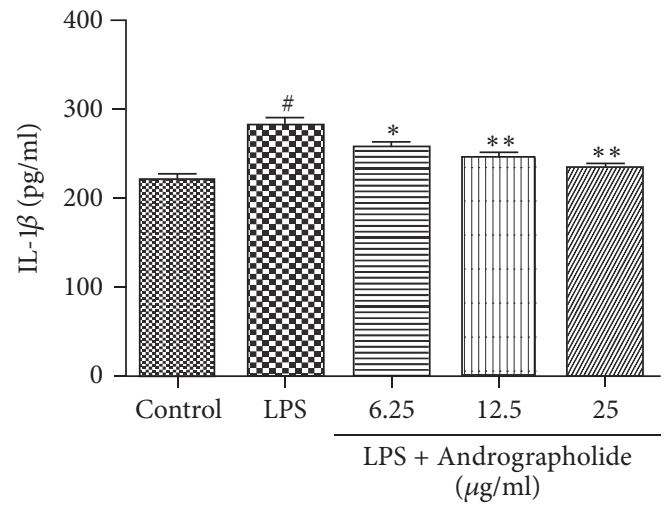

(b)

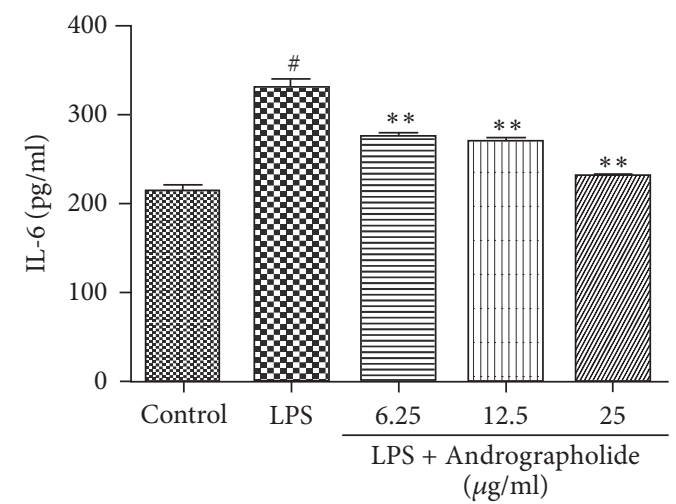

(c)

FIGURE 3: Effect of Andrographolide on the secretion of TNF- $\alpha$, IL-1 $\beta$, and IL- 6 induced by LPS. \# indicates the control group compared with the LPS group $(P<0.05)$; * and $* *$ indicate the Andrographolide group compared with the LPS group $(P<0.05)$ and $(P<0.01)$. Results of TNF $\alpha(a)$, IL-1 $\beta$ (b), and IL-6 (c) secretion are representative of three $(\mathrm{a}-\mathrm{c})$ independent experiments.

Andrographolide treated cells and was significantly lower than that of the LPS group $(P<0.01)$.

3.5. Effect of Andrographolide on the Suppression of LPSInduced $N F-\kappa B / M A P K$ Pathway. Since IkBa is phosphorylated after stimulation by LPS, followed by the release of the NF- $\kappa \mathrm{B}$-p65 protein into the nucleus, and promotes the production of proinflammatory cytokines, we next evaluated the effect of Andrographolide on the inhibition of LPSinduced NF- $\kappa \mathrm{B}$ and MAPK pathways by a western blot. As shown in Figure 6, the levels of phosphorylated p65 and phosphorylated $\mathrm{IkBa}$ in the NF- $\kappa \mathrm{B}$ signaling pathway were significantly increased, while the levels of total IkBa in the NF- $\kappa \mathrm{B}$ signaling pathway were significantly reduced in LPS group. However, the levels of p65 and $\mathrm{IkBa}$ phosphorylation in the $\mathrm{NF}-\kappa \mathrm{B}$ signaling pathway were significantly reduced in the Andrographolide groups (doses of $6.25,12.5$, and $25 \mathrm{~g} / \mathrm{ml}$ ) compared with the LPS group in a dose-dependent manner. In contrast, the level of total IkBa increased significantly with the increasing doses of Andrographolide. The above results indicate that the Andrographolide can suppress the LPS-induced NF- $\kappa \mathrm{B}$ pathway.

As shown in Figure 7, the phosphorylation of JNK, ERK1/2, and p38 in the MAPK signaling pathway was significantly increased in LPS-stimulated samples, but the levels of p-JNK, p-ERK1/2, and p-p38 significantly decreased in the Andrographolide group (doses of $6.25,12.5$, and $25 \mathrm{~g} / \mathrm{ml}$ ) in a dose-dependent manner compared with the LPS group. These results suggest that Andrographolide can also suppress the LPS-induced MAPK pathway.

\section{Discussion}

Andrographis has many active components that have antiinflammatory properties. Current research has shown that various active ingredients of Andrographis affect immune function, interacting with the platelet activating factor receptor, improving the nitric oxide levels in the body, scavenging oxygen free radicals, and inhibiting various proinflammatory cytokines, thus exhibiting a potent anti-inflammatory effect [14].

Andrographolide, the major active constituent extracted from Andrographis, occupies 70\% of the Andrographis extract and has been reported to have many pharmacological properties, (e.g., it has antibacterial, antiviral, and antiplatelet properties, stimulates cellular differentiation, protects the liver, is a cholagogue, has antitumor properties, and is immunoregulatory). In addition, previous studies have shown that Andrographolide can inhibit increases in capillary permeability caused by xylene and acetic acid in mice [15]. Moreover, it has obvious anti-inflammatory effect, such as in laryngitis, 


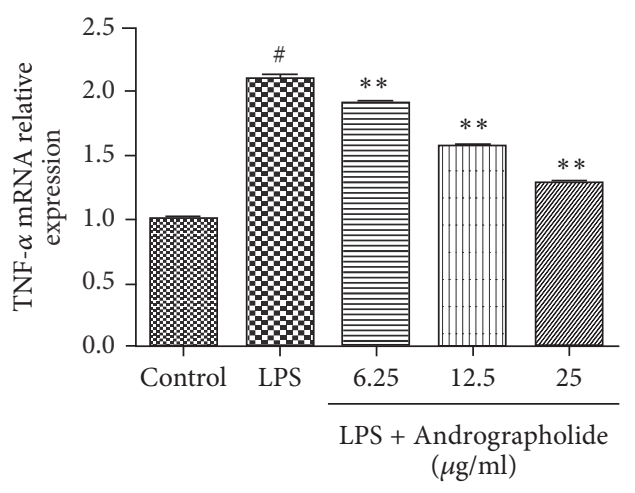

(a)

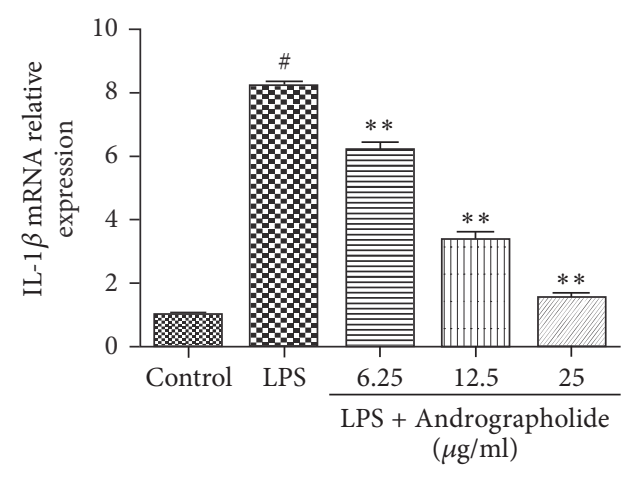

(b)

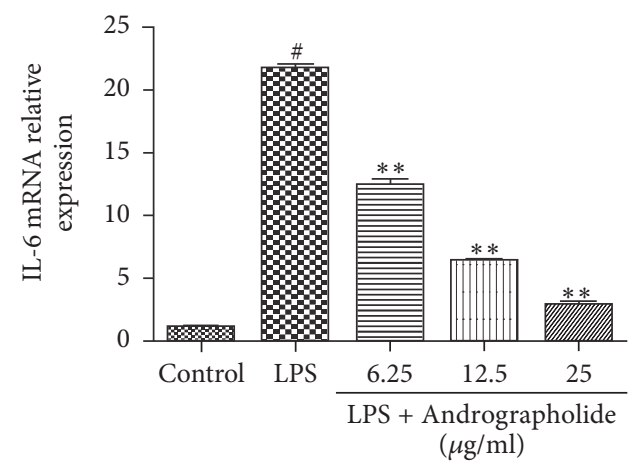

(c)

FIgURE 4: Effect of Andrographolide on the mRNA expression of TNF- $\alpha$, IL-1 $\beta$, and IL-6 induced by LPS. \# indicates the control group compared with the LPS group $(P<0.05)$ and $* *$ indicates the Andrographolide group compared with the LPS group $(P<0.01)$. Results of TNF $\alpha(a)$, IL-1 $\beta$ (b), and IL-6 (c) mRNA expression are representative of six (a-c) independent experiments.

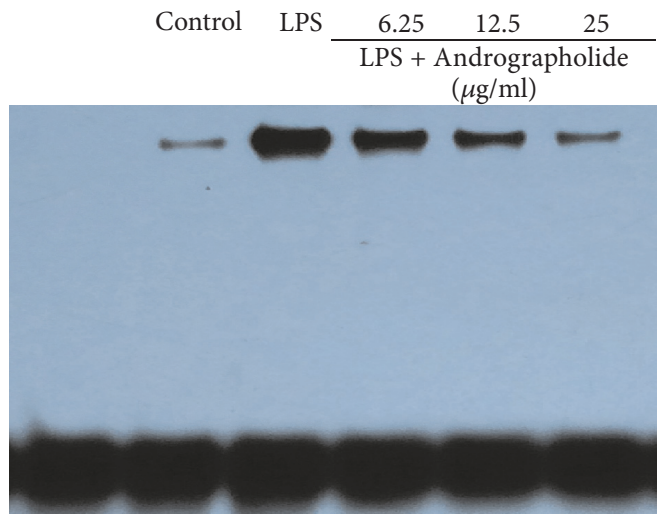

(a)

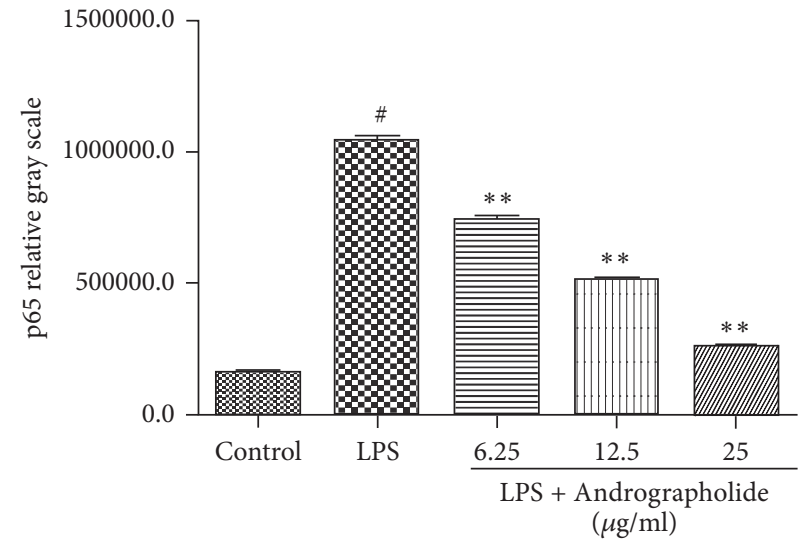

(b)

FIGURE 5: Effect of Andrographolide on nuclear level of transcription factor NF-kB. \# indicates the control group compared with the LPS group $(P<0.05) ; * *$ indicates the Andrographolide group compared with the LPS group $(P<0.01)$. Results of the nuclear level of NF-kB probe binding activity (a) and gray scale (b) are representative of three (a-b) independent experiments.

upper respiratory tract infection, and rheumatoid arthritis [16-22].

Inflammation is a complex process involving the interaction between an organism and pathogens, with the results of these complex interactions to induce macrophage activation [23]. In addition, activated macrophages can eliminate invading infectious microbes and trigger the release of inflammatory cytokines, such as TNF- $\alpha$, IL-1 $\beta$, and IL-6, and then complete a variety of immune function in response to these cytokines [24]. Existing research shows that LPS is a potent inducer of inflammation and can stimulate macrophages to produce TNF- $\alpha$, IL- $1 \beta$, and IL- 6 . Thus, the 


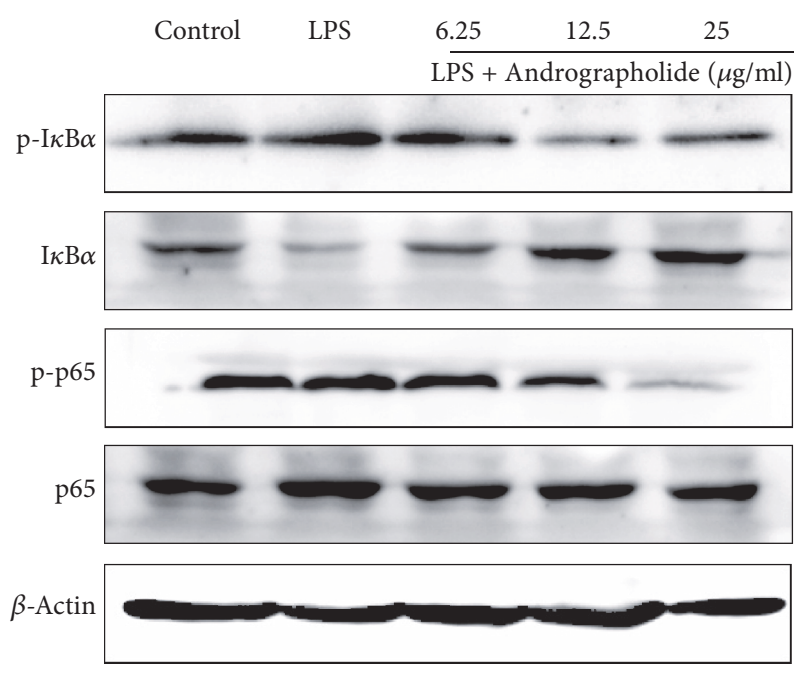

(a)

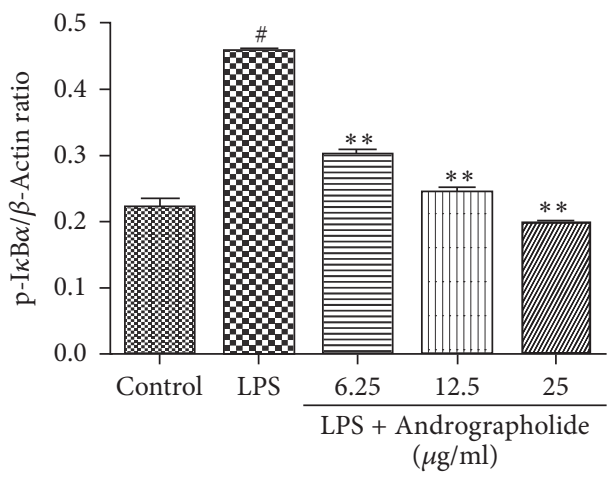

(b)

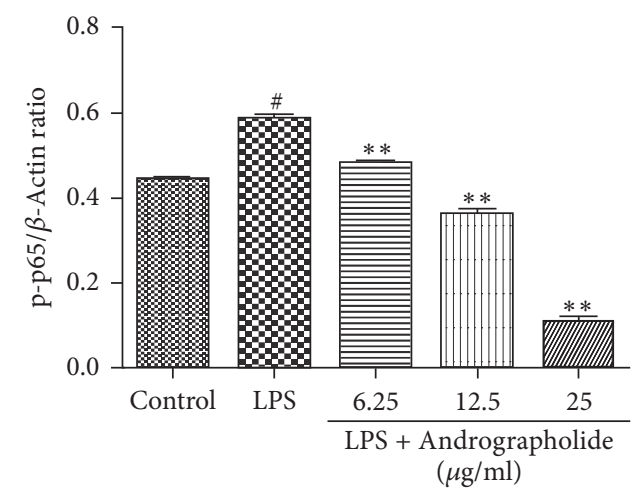

(c)

FIGURE 6: Effect of Andrographolide on the activation of NF- $\kappa$ B pathways of RAW264.7 cells induced by LPS. \# indicates the control group compared with the LPS group $(P<0.05) ; * *$ indicates the Andrographolide group compared with the LPS group $(P<0.01)$. Results of western blot (a), gray scale (b) and (c) are representative of three $(a-c)$ independent experiments.

organic damage caused by inflammation can be reduced by inhibiting the excessive production of inflammatory cytokines [25].

In the present study, an in vitro model of inflammation was induced by LPS in mouse RAW264.7 cells, followed by treatment with different concentrations of Andrographolide. Our results demonstrated that Andrographolide significantly inhibits the expression of TNF- $\alpha$, IL-6, and IL- $1 \beta$ in LPS-stimulated RAW264.7 cells. Furthermore, we also found that Andrographolide has in vitro anti-inflammatory effects.

Andrographolide can inhibit the expression of TNF$\alpha$, IL- $1 \beta$, and IL- 6 in LPS-stimulated macrophages. Thus, the exploration of the anti-inflammatory mechanism of Andrographolide is significance [26]. The NF- $\kappa$ B and MAPK signaling pathways are two extremely classical activation pathways in the process of LPS-induced signal transduction [27]. Under normal resting conditions, NF- $\kappa \mathrm{B}$ and $\mathrm{IkBa}$ aggregate into a trimer within the cytoplasm. In response to LPS, IkBa is predominately phosphorylated and subsequently degraded, which frees NF- $\kappa \mathrm{B}-\mathrm{p} 65$ into the nucleus, and gene transcription of various proinflammatory factors is initiated $[28,29]$.

MAPK can also adjust the synthesis and release of the proinflammatory factors, p38, JNK, and ERK, which are three important pathways primarily involved in the inflammatory responses. When activated by external stimuli, p38, JNK, and ERK phosphorylation is increased and related proinflammatory cytokines will begin to be expressed [30]. Furthermore, the present study explores the antiinflammatory mechanism of Andrographolide regarding the NF- $\kappa \mathrm{B}$ and MAPKs pathways. Our results demonstrated that LPS could induce the phosphorylation of IkBa, NF- $\kappa \mathrm{B}-\mathrm{p} 65$, p38, JNK, and ERK, but the phosphorylation of IkBa, NF$\kappa \mathrm{B}-\mathrm{p} 65, \mathrm{p} 38, \mathrm{JNK}$, and ERK was significantly inhibited when the cells were treated with Andrographolide. Consequently, the inhibition of the NF- $\kappa$ B and MAPK pathways and the production of proinflammatory cytokines were inhibited, thus indicating that its anti-inflammatory effect was exerted via these pathways. 


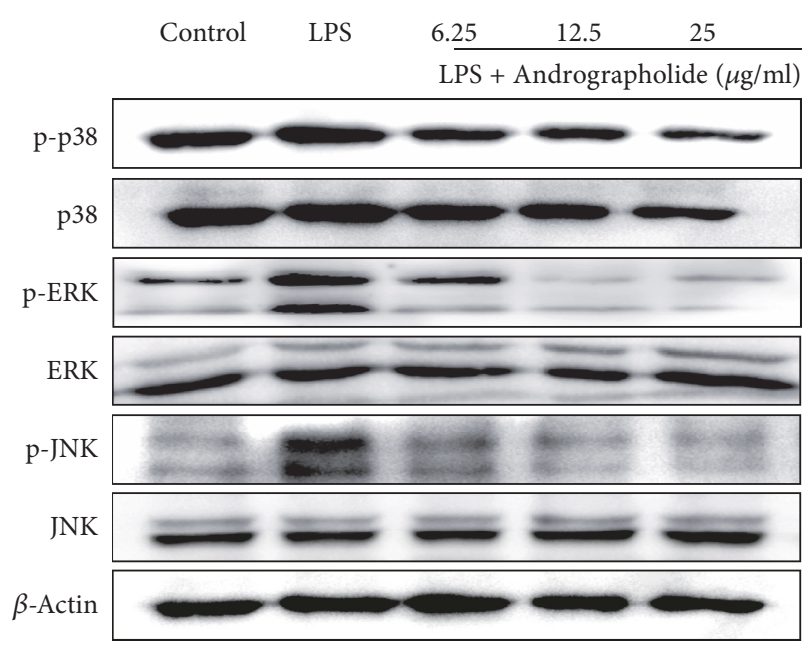

(a)

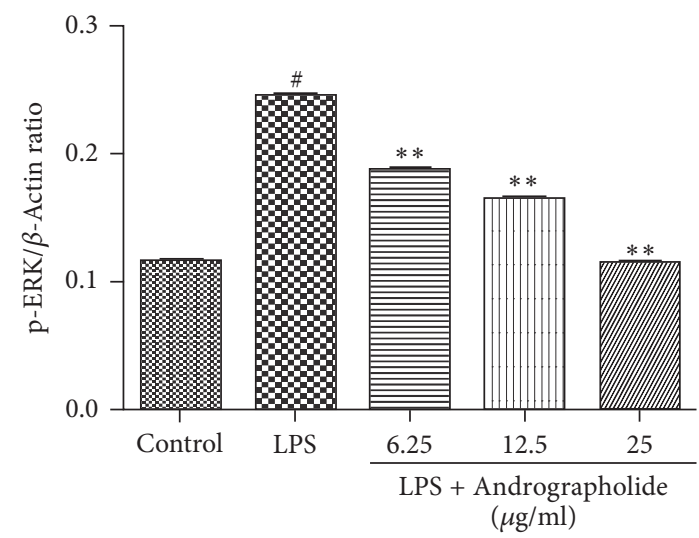

(c)

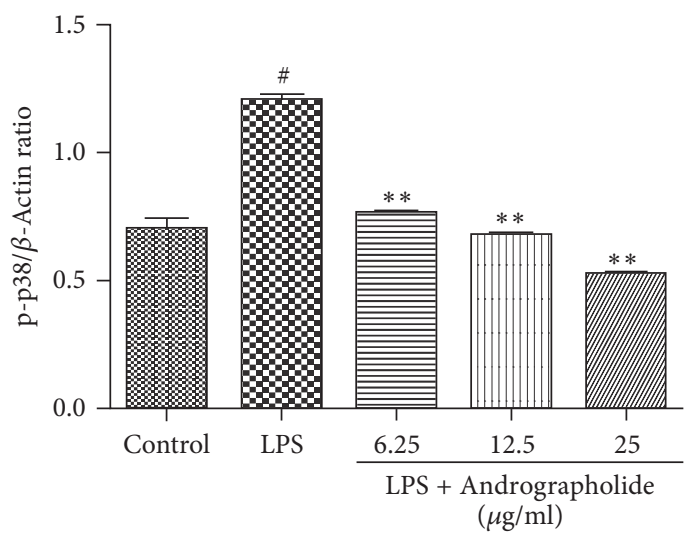

(b)

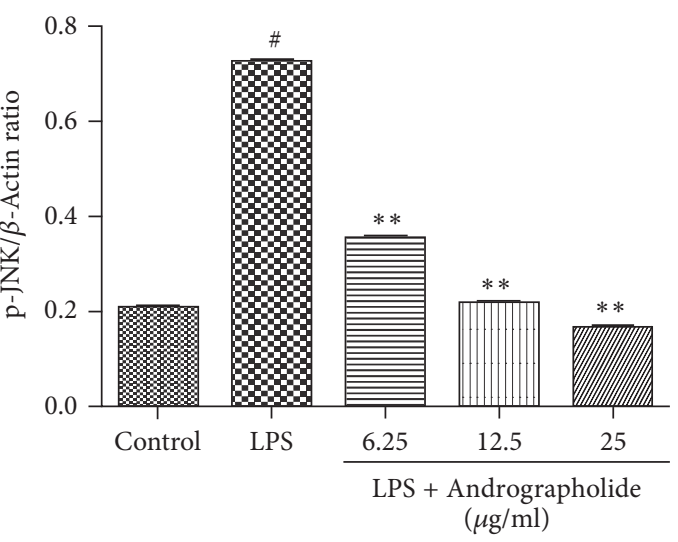

(d)

FIGURE 7: Effect of Andrographolide on the activation of MAPK pathways of RAW264.7 cells induced by LPS. \# indicates the control group compared with the LPS group $(P<0.05)$; ** indicates the Andrographolide group compared with the LPS group $(P<0.01)$. Results of western blot (a), gray scale (b), (c) and (d) are representative of four (a-d) independent experiments.

\section{Conclusions}

Andrographolide has anti-inflammatory effect and significantly inhibits the expression of TNF- $\alpha$, IL- 6 , and IL- $1 \beta$ in LPS-stimulated RAW264.7 cells. Its anti-inflammatory mechanism may be through the inhibition of NF- $\kappa \mathrm{B}$ and MAPKs signaling pathway.

\section{Conflicts of Interest}

The authors declare that they have no conflicts of interest regarding the publication of this paper.

\section{Authors' Contributions}

Yu Li, Shengnan He, and Jishun Tang contributed equally to this work.

\section{Acknowledgments}

This work was supported by grants from the National Key Research and Development Program of China
(2016YFD0501009) and the Project of Modern Agricultural Industry and Technology System of Anhui Province (2016-2020).

\section{References}

[1] B. Levine, N. Mizushima, and H. W. Virgin, "Autophagy in immunity and inflammation," Nature, vol. 469, no. 7330, pp. 323-335, 2011.

[2] F. Li, D. Liang, Z. Yang et al., "Astragalin suppresses inflammatory responses via down-regulation of NF- $\kappa$ B signaling pathway in lipopolysaccharide-induced mastitis in a murine model," International Immunopharmacology, vol. 17, no. 2, pp. 478-482, 2013.

[3] X. P. Li, C. L. Zhang, P. Gao, J. Gao, and D. Liu, "Effects of andrographolide on the pharmacokinetics of aminophylline and doxofylline in rats," Drug Research, vol. 63, no. 5, pp. 258262, 2013.

[4] A. Varma, H. Padh, and N. Shrivastava, "Andrographolide: a new plant-derived antineoplastic entity on horizon," EvidenceBased Complementary and Alternative Medicine, vol. 2011, Article ID 815390, 9 pages, 2011. 
[5] T. Zhu, D. X. Wang, W. Zhang et al., "Andrographolide protects against LPS-induced acute lung injury by inactivation of NF«B," PLoS ONE, vol. 8, no. 2, Article ID e56407, 2013.

[6] C. V. Chandrasekaran, P. Thiyagarajan, H. B. Deepak, and A. Agarwal, "In vitro modulation of LPS/calcimycin induced inflammatory and allergic mediators by pure compounds of Andrographis paniculata (King of bitters) extract," International Immunopharmacology, vol. 11, no. 1, pp. 79-84, 2011.

[7] J.-M. Zhang and J. An, "Cytokines, inflammation, and pain," International Anesthesiology Clinics, vol. 45, no. 2, pp. 27-37, 2007.

[8] X. Jin, S. N. Shi, and D. F. Zhang, "Study on composition of andrographolide," Chinese Herbal Medicines, vol. 43, pp. 47-50, 2014.

[9] M. Rossol, H. Heine, U. Meusch et al., "LPS-induced cytokine production in human monocytes and macrophages," Critical Reviews in Immunology, vol. 31, pp. 379-446, 2011.

[10] A. A. Abu-Ghefreh, H. Canatan, and C. I. Ezeamuzie, "In vitro and in vivo anti-inflammatory effects of andrographolide," International Immunopharmacology, vol. 9, no. 3, pp. 313-318, 2009.

[11] S. H. Diks, D. J. Richel, and M. P. Peppelenbosch, "LPS signal transduction: the picture is becoming more complex," Current Topics in Medicinal Chemistry, vol. 4, no. 11, pp. 1115-1126, 2004.

[12] Z. Meng, C. Yan, Q. Deng, D.-F. Gao, and X.-L. Niu, "Curcumin inhibits LPS-induced inflammation in rat vascular smooth muscle cells in vitro via ROS-relative TLR4-MAPK/NF- $\kappa \mathrm{B}$ pathways," Acta Pharmacologica Sinica, vol. 34, no. 7, pp. 901911, 2013.

[13] L.-H. Qin, Z.-W. Zheng, L. Kong, J. Lü, Y.-X. Shi, and Y.-P. Li, "Andrographolide inhibits expression of TNF- $\alpha$ and IL-12 in activated macrophages," Academic Journal of Second Military Medical University, vol. 32, no. 7, pp. 717-720, 2011.

[14] D. Talei, A. Valdiani, M. Maziah, S. R. Sagineedu, and R. Abiri, "Salt stress-induced protein pattern associated with photosynthetic parameters and andrographolide content in Andrographis paniculata Nees," Bioscience, Biotechnology and Biochemistry, vol. 79, no. 1, pp. 51-58, 2015.

[15] H. Du, X. Niu, and H. Y. Li, "Andrographolide microemulsion anti-inflammatory effects," Chinese Journal of Traditional Medicine, pp. 94-96, 2012.

[16] Y. F. Xia, B. Q. Ye, Y. D. Li et al., "Andrographolide attenuates inflammation by inhibition of NF-kB activation through covalent modification of reduced cysteine," Journal of Immunology, vol. 173, no. 6, pp. 4207-4217, 2004.

[17] J. Batkhuu, K. Hattori, F. Takano et al., "Suppression of NO production in activated macrophages in vitro and ex vivo by neoandrographolide isolated from Andrographis paniculata," Biological \& Pharmaceutical Bulletin, vol. 25, pp. 1169-1174, 2002.

[18] E. Amroyan, E. Gabrielian, A. Panossian, G. Wikman, and H. Wagner, "Inhibitory effect of andrographolide from Andrographis paniculata on PAF-induced platelet aggregation," Phytomedicine, vol. 6, no. 1, pp. 27-31, 1999.

[19] A. Puri, R. Saxena, R. P. Saxena, K. C. Saxena, V. Srivastava, and J. S. Tandon, "Immunostimulant agents from Andrographis paniculata," Journal of Natural Products, vol. 56, no. 7, pp. 995999, 1993.

[20] Y. C. Shen, C. F. Chen, and W. F. Chiou, "Andrographolide prevents oxygen radical production by human neutrophils: possible mechanism(s) involved in its anti-inflammatory effect,"
British Journal of Pharmacology, vol. 135, no. 2, pp. 399-406, 2002.

[21] Y.-C. Shen, C.-F. Chen, and W.-F. Chiou, "Suppression of rat neutrophil reactive oxygen species production and adhesion by the diterpenoid lactone andrographolide," Planta Medica, vol. 66, no. 4, pp. 314-317, 2000.

[22] A. Kapil, I. B. Koul, S. K. Banerjee, and B. D. Gupta, "Antihepatoxic effects of major diterpenoid constituents of Andrographis paniculata," Biochemical Pharmacology, vol. 46, no. 1, pp. 182185, 1993.

[23] X. Zeng, H. C. Bi, and M. Huang, "Research progress of drug control in the process of inflammatory reaction," Acta Pharmacologica Sinica, vol. 7, pp. 773-779, 2011.

[24] P. Rainard and C. Riollet, "Innate immunity of the bovine mammary gland," Veterinary Research, vol. 37, no. 3, pp. 369400, 2006.

[25] K. Takeda and S. Akira, “TLR signaling pathways," Seminars in Immunology, vol. 16, no. 1, pp. 3-9, 2004.

[26] Q.-Q. Zhang, Y. Ding, Y. Lei et al., “Andrographolide suppress tumor growth by inhibiting TLR4/NF-kB signaling activation in insulinoma," International Journal of Biological Sciences, vol. 10, no. 4, pp. 404-414, 2014.

[27] M. Yamamoto, S. Sato, H. Hemmi et al., "Essential role for TIRAP in activation of the signalling cascade shared by TLR2 and TLR4," Nature, vol. 420, no. 6913, pp. 324-329, 2002.

[28] J. C. Rosa, F. S. Lira, R. Eguchi et al., "Exhaustive exercise increases inflammatory response via toll like receptor-4 and NF- $\kappa$ Bp65 pathway in rat adipose tissue," Journal of Cellular Physiology, vol. 226, no. 6, pp. 1604-1607, 2011.

[29] H.-Y. Kim, K. W. Hwang, and S.-Y. Park, "Extracts of Actinidia arguta stems inhibited LPS-induced inflammatory responses through nuclear factor- $\kappa \mathrm{B}$ pathway in Raw 264.7 cells," Nutrition Research, vol. 34, no. 11, pp. 1008-1016, 2014.

[30] L. Koch, D. Frommhold, K. Buschmann, N. Kuss, J. Poeschl, and P. Ruef, "LPS- and LTA-induced expression of IL-6 and TNF- $\alpha$ in neonatal and adult blood: role of MAPKs and NF$\kappa \mathrm{B}$, , Mediators of Inflammation, vol. 2014, Article ID 283126, 8 pages, 2014. 


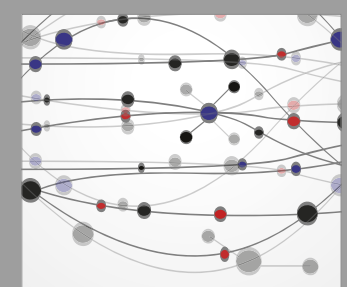

The Scientific World Journal
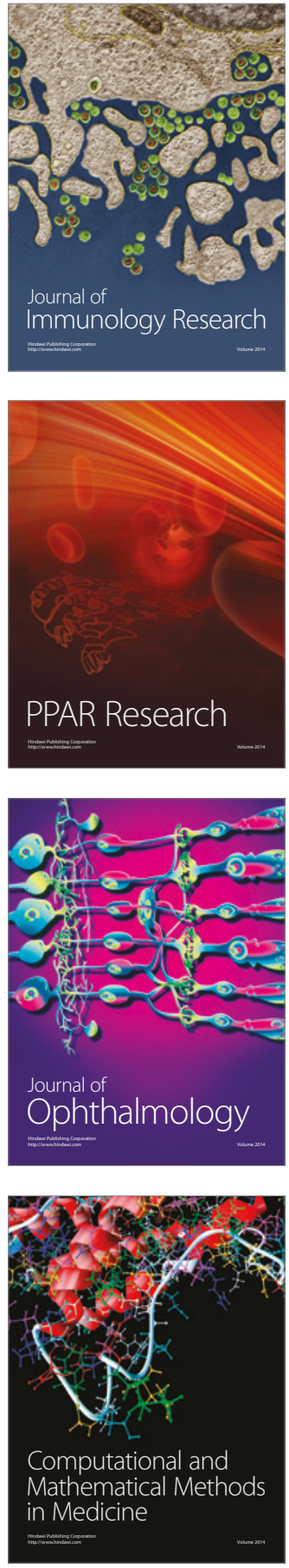

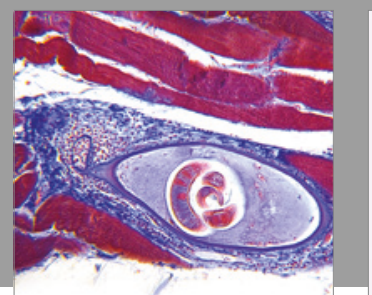

Gastroenterology Research and Practice
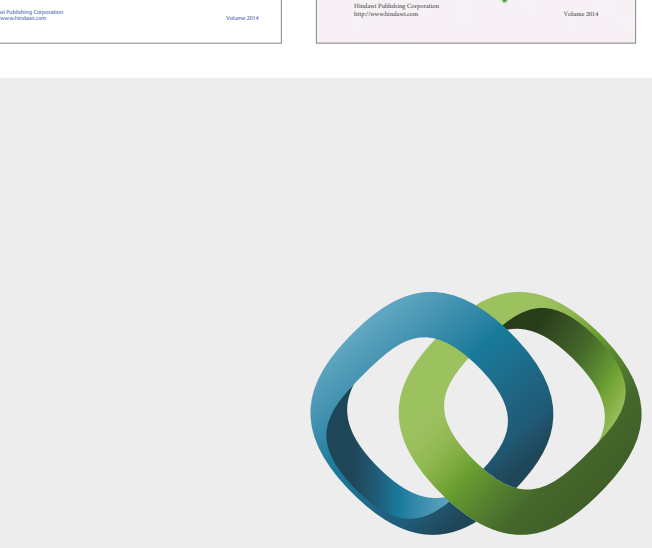

\section{Hindawi}

Submit your manuscripts at

https://www.hindawi.com
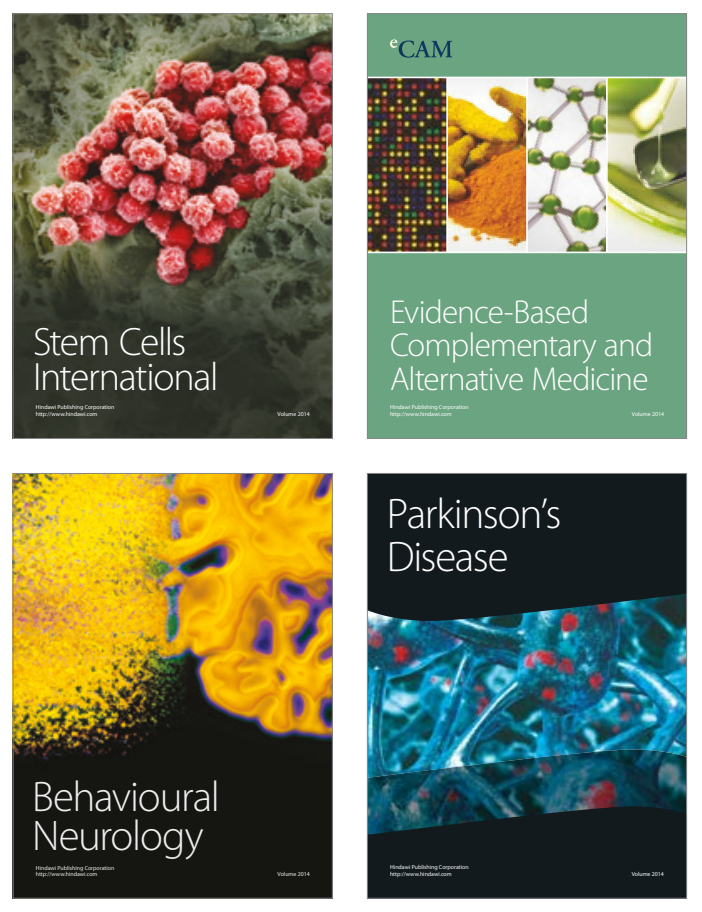
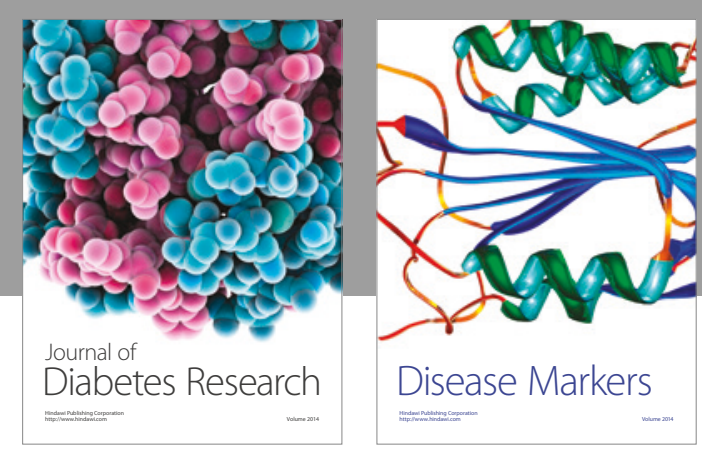

Disease Markers
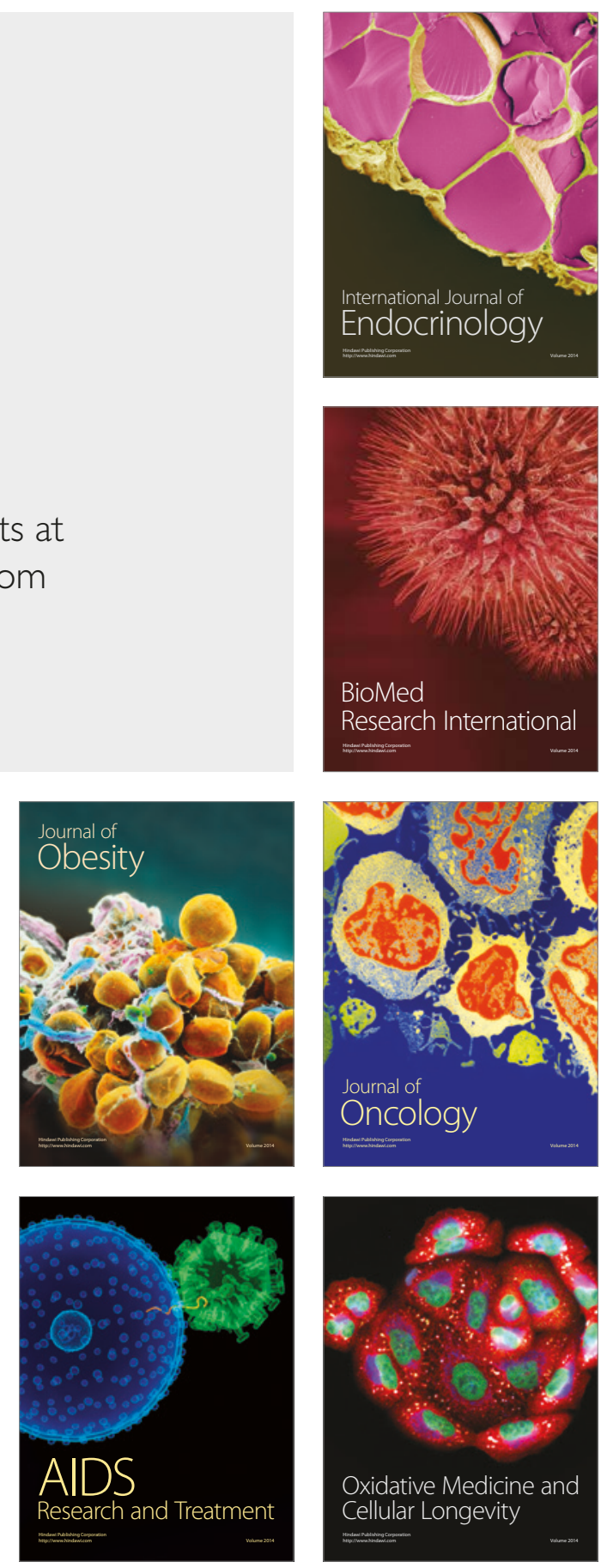